\title{
Infância e Cidade: inventar espaços e modos de viver
}

\author{
Gislei Domingas Romanzini Lazzarotto, ${ }^{I, \star ~ M a r i a ~ L i v i a ~ d o ~ N a s c i m e n t o ~}{ }^{I I}$ \\ ${ }^{I}$ Universidade Federal do Rio Grande do Sul, Porto Alegre, RS, Brasil \\ II Universidade Federal Fluminense, Niterói, RJ, Brasil
}

\begin{abstract}
Resumo
Nossa experiência com pesquisa no âmbito do Estatuto da Criança e do Adolescente evidencia práticas institucionais que relacionam o movimento da criança na cidade com práticas de recolher e abrigar em determinados estabelecimentos. Problematizamos como as ligações entre a infância e a cidade vão sendo constituídas na produção das relações de que visam governar a vida, desenvolvendo um estudo genealógico, referenciado em Michel Foucault, com duas linhas de análise: a criação de mecanismos que articulam a infância, a família e o espaço urbano, na sociedade moderna, considerando os estudos de Jacques Donzelot e Philippe Ariès; e os registros das diretrizes de referência na política da infância no Brasil (Código de Menores - 1927 e 1979 , Estatuto da Criança e do Adolescente - 1990). Entre os modos de governar e inventar a infância e a cidade no Brasil encontramos o diagrama de um sentimento de sujeito de direito infanto-juvenil.
\end{abstract}

Palavras-chave: infância; cidade; relações de poder.

\section{Childhood and City: inventing spaces and ways of living}

\begin{abstract}
Our researching experience concerning the Child and Adolescent Statute highlights institutional practices that relate the movement of the child in the city with practices of gathering and sheltering in certain establishments. We problematize how the relations between childhood and city are built in power relations aiming governing life, by developing a genealogic study based on Michel Foucault, with two analyses paths: the creation of mechanisms that articulate the childhood, the family and the urban space in modern society, considering Jacques Donzelot and Philippe Ariès'studies; and the records of the reference guidelines on childhood policy in Brazil (Minors' Code - 1927 and 1979, Child and Adolescent Statue - 1990). Among the ways of governing and inventing childhood and the city in Brazil, we find the diagram of a sense of subject of children's rights.
\end{abstract}

Keywords: childhood; city; power relationships.

Andar pela cidade. Caminhar. Atividade cada vez menos considerada em nosso cotidiano. As calçadas das ruas são tomadas como lugar de pisar, andar por cima para acessar o ônibus, o trem, o automóvel, e assim chegar ao destino. Como esse andar compõe nossos trajetos e se fazem destino? Quem passou por ali? Do tempo de quantas vidas caminhadas essas pedras são feitas?

E se pudéssemos calçar a calçada e viver os acontecimentos que sua história conta?

No Rio de Janeiro, em frente à igreja da Candelária vemos no chão, pintado em vermelho, o desenho de oito corpos infanto-juvenis. É

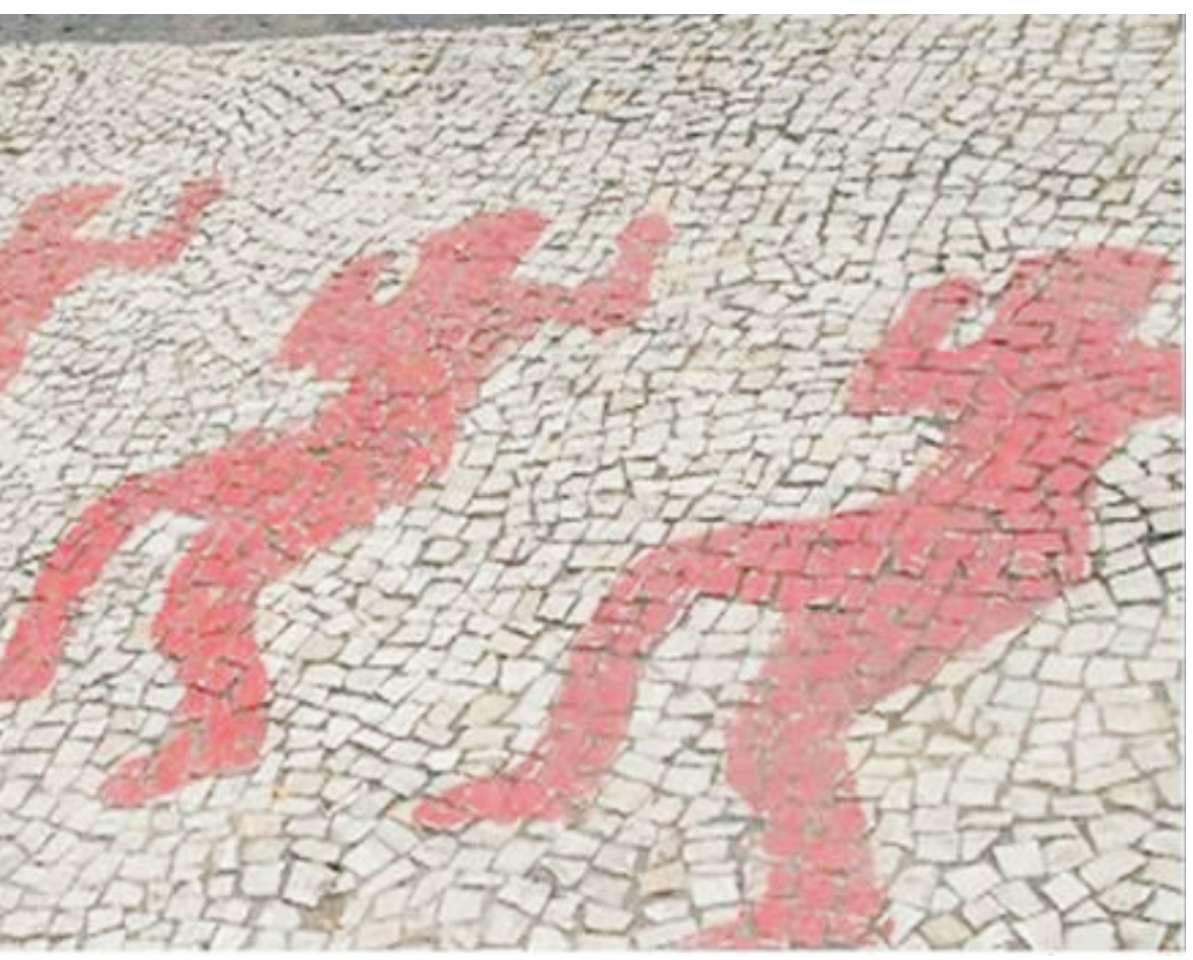
uma marca da cidade. Em Porto Alegre o jornal Zero Hora (VIDA..., 1993) traz também uma imagem. Essa do ano de 1993, publicada

^Endereço para correspondência: Universidade Federal do Rio Grande do Sul,
Instituto de Psicologia, Departamento de Psicologia Social e Institucional. Ra-
miro Barcelos, 2600 - sala 300 F, Santana. Porto Alegre, RS - Brasil - CEP:
90035-003. Caixa-postal: 90130151 . E-mail: gislei.ufrgs@gmail.com, mliviacerca de dois meses antes da chacina ocorrida no Rio lembrada pelos contornos de corpos em vermelho. O jornal destaca uma fotografia de meninos saindo dos canais do esgoto, onde viviam, em frente à Prefeitura da cidade de Porto Alegre, e são chamados pelo veículo de informação de "tartarugas ninja". 


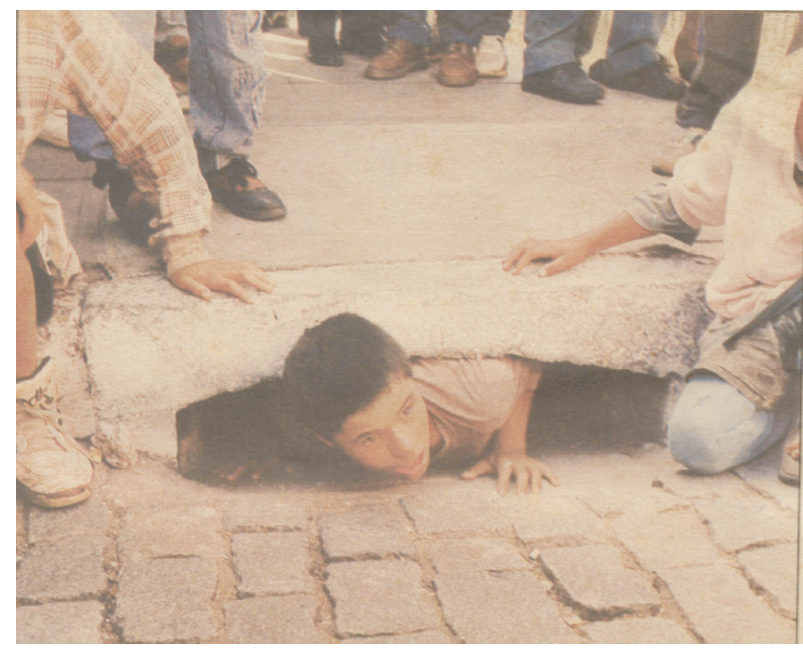

Passamos a indagar o que teria capturado nossa atenção para forçar nosso olhar nesta direção, evidenciando que se tratavam mais do que registros de fatos. Seria tão evidente a associação da vida da criança na rua com a violência e o descuido? O que enunciam as crianças ao experimentarem as ruas de nossas cidades? Diante de tais indagações encontramos a inspiração em Foucault (2003, p. 339) para prosseguir, quando propõe a função teórico-política da acontecimentalização que envolve a ruptura das evidências, "essas evidências sobre as quais se apoiam nosso saber, nossos consentimentos, nossas práticas", um processo que consiste em reencontrar conexões, os encontros, os jogos de forças, as estratégias, que, em um dado momento formaram o que, em seguida, funcionará como evidência, universalidade, necessidade.

A passagem do registro das imagens ao movimento de acontecimentalizar e como elas se produziram no campo de forças que enunciava três anos antes a criação do Estatuto da Criança e do Adolescente (BRASIL, 1990) possibilita prosseguir no traçado deste mapa cidade-infância-visibilidade. As imagens da infância impressas na memória que se tornam traçado do passo na Candelária, no Rio de Janeiro, e que se faz fotografia da história dos arredores da Prefeitura, em Porto Alegre, lançam a pista do espaço revisitado pelo exercício no tempo, indicando como as relações de poder nos produzem cá e lá. Como estas duas imagens, referenciadas no mesmo ano - 1993 - em duas capitais brasileiras, produzem modos de ver e dizer a infância na cidade? Como essa questão compõe a produção de conhecimento no percurso das pesquisadoras autoras deste texto?

\section{Nossas implicações, analisadores e percurso metodológico}

Pensar a infância e a cidade no Brasil, no âmbito das produções da psicologia, nos leva a problematizar o regime de visibilidade que vem sendo constituído a respeito da infância que experimenta a cidade. Nessa direção, vamos construindo um analisador a respeito de como o saber da psicologia sustenta uma determinada concepção de infância e dos modos de viver a cidade.
Uma questão que nos parece ambiciosa para contemplar neste artigo é o quanto a temática infância e cidade ficou à margem de nossos estudos em psicologia.

Neste percurso de reflexão fomos construindo algumas questões para direcionar nossa escrita: Como a infância se constitui como questão na relação com a cidade? Como podemos traçar um mapa da multiplicidade dos modos de subjetivar da infância nos modos de viver a cidade na experiência brasileira? No movimento de problematizar o tema em estudo encontramos certo incômodo, como se pouco tivéssemos a dizer sobre a relação infância e cidade. Passamos a indagar o que levaria pesquisadoras que trabalham com o Estatuto da Criança e do Adolescente, em diferentes contextos como os das medidas de proteção e as socioeducativas se sentirem incapazes para falar deste assunto quando relacionado à problematização da cidade. Percebemos que fazer este movimento implicava em ultrapassar o que se coloca como limite entre as pesquisadoras e o tema de estudo, para problematizar a relação que produziu esta posição de análise. Assim, foi necessário construir um modo de pesquisar que acolhesse a diferença que esta experiência provocava em nosso regime de visibilidade a respeito da infância. O que se apresentava como incômodo e mutismo sobre o que dizer sinalizava a demanda por experimentar algo que lançava nosso olhar para outras questões, as quais naquele momento, passavam a compor o regime de visibilidade que produzia nosso saber. Portanto, era preciso experimentar o que a questão "infância e cidade" provocava na trajetória da experiência de nosso pesquisar. Ao problematizar o visível e o enunciável na produção do saber, Deleuze (1988, p. 60) dialoga com a obra de Michel Foucault e destaca que o saber "definese por suas combinações do visível e do enunciável" próprias para cada formação histórica. $\mathrm{O}$ autor destaca que "o saber é um agenciamento prático, um 'dispositivo' de enunciados e de visibilidades” (Deleuze, 1988, p. 60), pois cada formação histórica vê e faz ver o que pode, assim como diz o que pode.

A sensação inicial de ausência do analisador cidade poderia ser exatamente uma linha de problematização das relações de poder que nos posicionaram neste lugar, considerando o modo como a condição da infância é pensada e constituída ao compor um campo de exercício das relações de poder na função que a cidade ocupa em determinado momento histórico. Ao produzirmos saberes estamos constituindo relações de poder num regime de práticas que situa a posição que ocupamos na formação histórica deste discurso que aborda a infância.

Assim, passamos a analisar o modo como as relações, o tempo e a crítica constituíam o percurso de nossas pesquisas, as condições de emergência de questões que traziam a associação entre a infância e a cidade com a experiência da violência e das violações de direitos, como tão bem expressam as imagens que dispararam este texto. Nesse processo, uma linha de análise já tomava forma: não se tratava da infância e da cidade, como conceitos universais e dados, mas uma determinada 
infância que se tornava enunciável e foco de exercício de relações de poder considerando determinados modos de viver e traçar uma cidade.

Ao trabalharmos com pesquisas no contexto de políticas brasileiras direcionadas ao atendimento infanto-juvenil (NASCIMENTO, 2014a, 2014b; LAZZAROTTO, 2012, 2014), nossas análises tratam de práticas institucionais, cujos mecanismos relacionam o movimento da criança na cidade com os procedimentos de recolher e abrigar em determinados estabelecimentos que territorializam o espaço de circulação desta população. Esses espaços de análise se impõem porque existe uma população infantojuvenil que não pode percorrer as ruas, ou só está lá quando no desvio da norma, quando está só de passagem para em seguida ser recolhida. Há uma interdição de suas presenças fora dos lugares instituídos e esperados para a experiência da infância, o que nos leva a indagar como estes lugares vão sendo determinados na construção histórica do espaço citadino. Mas o jogo de forças que constitui esta interdição estaria presente, também, no modo como estávamos constituindo nossas análises? A problematização da cidade estaria produzindo um novo jogo de forças em relação ao regime de visibilidade das práticas institucionais com a criança sobre as quais trabalhamos?

Nossa reflexão prossegue na perspectiva de um trabalho genealógico, o qual conforme Michel Foucault (1979, p. 154) é movido pelas experiências de "combates, linhas de força, pontos de confronto, tensões" que problematizam a história em seu jogo político e produtor de verdades. Ao ser entrevistado numa conversa sobre a geografia, o autor aborda questões no debate a respeito de como ocorrem as demarcações do espaço que fazem aflorar processos de poder. "A descrição espacializante dos fatos discursivos desemboca na análise dos efeitos de poder que lhe estão ligados" (FOUCAULT, 1979, p. 159). Desse modo, destaca a importância do estudo das grandes estratégias da geopolítica, bem como das pequenas táticas de um habitat, da arquitetura institucional, da sala de aula ou de uma organização hospitalar, pois esta "história dos espaços" é, ao mesmo tempo, uma "história dos poderes" articuladas às implantações econômico-políticas (FOUCAULT, 1979, p. 212). Esta análise nos aproxima da problematização de como vai sendo constituída uma tecnologia do poder associada aos modos de governar a vida na organização da cidade com a infância.

Neste sentido, outra pista para nosso processo de análise se refere ao trabalho de Philippe Ariès (1981) a respeito da história social de criança e da família. Seus estudos problematizam, na constituição da vida moderna, uma relação muito precisa que vai sendo produzida na sociedade, entre a experiência do sentimento vinculado à família e à criança e uma organização particular do espaço urbano. Construindo esta trama de análise a obra $A$ polícia das famílias, de Jacques Donzelot (1986), também contribui para pensarmos essa questão à medida que o autor analisa como o sentimento moderno de família teria surgido nas camadas burguesas e nobres do Antigo Regime, estendendo-se para outras classes sociais. Ao compor sua reflexão a respeito de como o sentimento de família foi estendendo-se entre as classes sociais na articulação funcional entre o social e o econômico, o autor dialoga com o conceito de biopolítica de Michel Foucault.

Conforme os estudos de Foucault (2008) a respeito das relações de poder, nas sociedades ocidentais modernas, a partir do século XVIII, o biopoder envolve um conjunto dos mecanismos pelos quais as características biológicas fundamentais que constituem o ser humano passam a compor o funcionamento de uma política, uma estratégia de poder (FOUCAULT, 2008). Tal pensamento compõe com as análises de Donzelot (1986) que problematiza a inclusão da família, nos países europeus, entre as tecnologias políticas que irão investir sobre o corpo, a saúde, as formas de se alimentar e de morar, enfim, sobra a existência.

Ao nos reportarmos ao espaço nas cidades de nossos dias, fomos levadas pela memória de crianças que perderam suas vidas e permanecem na história da cidade ao serem desenhadas na calçada, ou aquelas refletidas no jornal saindo dos bueiros ao rés do chão, sempre no sentido fora da ordem. Tivemos que pensálas no contraponto de nossas práticas de pesquisadoras, experimentando o espaço em um tempo que atualiza nossa forma de problematizar e cria outros campos de visibilidade. Centradas que sempre estivemos nos estabelecimentos que dão forma a essas práticas institucionais direcionadas à infância, fomos situando os espaços que não sendo a casa da família e a escola, foram sendo designados, em diferentes épocas, como de recolhimento, abrigo, acolhimento. Portanto, não tínhamos somente os estabelecimentos que recolhem e abrigam no mapa da cidade, lá estavam também a casa da família e a escola como espaços designados à criança.

Essas práticas que cuidam, educam, recolhem, abrigam constituem procedimentos de governo da vida, que evidenciam a existência de um espaço territorializado sobre como deve ser a circulação dessa população, por vezes apagando o traçado de movimentos entre fronteiras que perdem sua possibilidade de exercício de relações para institucionalizar funções e posições. O presente artigo pretende problematizar como as relações entre a criança e a cidade vão sendo constituídas a partir de um modo de produção das relações de poder que visam governar a vida através de mecanismos organizados no encontro da geografia do espaço com os modos de viver das crianças.

Para tal percurso apresentamos duas linhas de análise: os estudos das relações de poder constituídas como modos de governar a vida, em específico na sociedade moderna com a criação de mecanismos que articulam a criança, a família e o espaço urbano, considerando os estudos de Michel Foucault, Jacques Donzelot e Philippe Ariès; e os registros das diretrizes de referência na política da infância no Brasil, que permitem constituir um mapa do ir e vir no tempo que se atualiza em nossas práticas, considerando a referência dos seguintes documentos: Código de Menores de 1927 (BRASIL, 1927), Código de Menores de 1979 (BRASIL, 1979), Estatuto da Criança e do Adolescente de 1990 (BRASIL, 1990). Desses estudos e documentos podemos referenciar outros, 
em especial, aqueles que orientam nossas práticas no contexto atual da intervenção da psicologia no que se refere às crianças, possibilitando a análise de possíveis arranjos sobre como o olhar da infância se faz presente nas disputas pela experimentação de um modo de viver a cidade, evidenciando na linha de finalização do texto tensões atuais que reverberam na memória das imagens disparadoras de nossa problematização.

\section{Sociedade moderna e o lugar da criança: pistas do espaço no tempo.}

A cidade nos leva a pensar na organização de uma população, em um determinado território que passa a ser marcado por uma arquitetura que possibilita morar, circular, estabelecer relações de convivência. Nos interessa nesse funcionamento como vai sendo governada a cidade no jogo político que coloca em discussão a problemática das práticas do Estado e de seus mecanismos para gerir suas formas de organização na relação com a infância. A escolha por evidenciar esta produção histórica e política, na sociedade moderna, está relacionada ao modo como a criança passa a fazer parte desse conjunto de mecanismos de governo da população, cujas práticas ainda tensionam nossas relações nas políticas de Estado que fazem funcionar a sociedade atual.

Convém não esquecer que o século XVIII foi também o século que inventou a criança. A sociedade em que adultos e crianças se encontram misturados no trabalho e nas diversões, nas festas e cerimônias, cede o lugar àquela - a nossa - em que a infância, cuidadosamente segregada, tornase um objeto específico de atenção no plano social: daí em diante, suas tarefas e brincadeiras terão o único objetivo de contribuir para a própria formação (SCHÉRER, 2009, p. 17).

Essa mudança na atitude em relação às crianças está relacionada à ascensão da burguesia, à crescente complexidade do funcionamento de uma sociedade industrial e a um conjunto de demandas que foram se desdobrando com o crescimento demográfico e a constituição de centros urbanos. Schérer (2009) evidencia como a máquina política-educativa das sociedades modernas produz mecanismos que buscam reprimir, transformar e controlar o indivíduo em cada etapa de seu desenvolvimento. Como potencial humano a ser colocado em reserva, a criança passa a ter à sua volta a mobilização de uma estratégia que está relacionada ao controle e ao preparo deste ser para uma nova sociedade, que vem acompanhada de um intenso desenvolvimento das técnicas pedagógicas e direcionamento de um lugar que marca a territorialização da pedagogia, a escola.

Assim, há um significativo processo de desenvolvimento da escola que acompanha o aumento da preocupação com a educação das crianças, sendo que a família passa a assumir o dever de enviá-las cada vez mais cedo à escola. Segundo Ariès (1981) a moral da época passava a convocar os pais a compor um elo com a escola para assegurar uma preparação para a vida, sendo que o espaço escolar passaria a ser um instrumento de disciplina severa articulado aos mecanismos de governo do Estado.
A infância é convocada a ocupar um campo social delimitado, deslocamento que cria funções determinadas para aqueles que devem cuidar desta faixa etária. Além disso, o aspeto pedagógico e normativo é acompanhando de uma outra faceta que a invenção da infância desperta um "sentimento da infância, de seu próprio valor, ultrapassando qualquer interesse e funcionalidade, que acabará tomando a forma de uma estética e de uma poesia, assim como de uma religião e de uma mística" (SCHÉRER, 2009, p. 20).

Neste sentido, entre os mecanismos que vão sendo investidos/aprimorados para constituir este modo de se relacionar com a criança, podemos destacar a associação da escola com o espaço familiar. Os estudos de Donzelot (1986) analisam como um sentimento moderno de família teria surgido, situando o singular lugar da família nas sociedades ocidentais modernas a partir de três imagens que emergem da vida cotidiana: 1) o tribunal de menores, em que criança e sua família ficam sob condicionamento das ações de técnicos sociais e magistrados, em que a relação entre os imperativos sociais e os comportamentos familiares sanciona uma correlação de forças em detrimento da família; 2) o abafamento vindo da própria família diante de atitudes que escapam à contradição familiar dos investimentos como o trabalho, a poupança, a familialização da sexualidade; 3) a família burguesa, cuja imagem envolve desde a saída da escola com aqueles que são esperados para serem mantidos em um conjunto de atividades planejadas numa perspectiva de liberação, mas num espaço protegido.

Os desdobramentos deste modo de instituir as relações entre infância, família e escola são estudados por Gouvêa e Jinzenji (2006), no Brasil, ao analisarem os discursos em circulação no contexto educacional escolar mineiro da primeira metade do século XIX, enfatizando a especificidade dos mecanismos de escolarização como forma de moralizar, em um projeto direcionado aos extratos considerados inferiores da população. Encontramos pistas relevantes a respeito dessas formações históricas, em terras brasileiras, no estudo de Corazza (2000) ao abordar as relações de poder-saber e das formas de subjetivação do modo moderno de constituir a infância.

$\mathrm{Na}$ elaboração dos estudos a respeito dessa problemática, tanto Schérer (2009), como Donzelot (1986), dialogam com o conceito de biopolítica de Michel Foucault, problematizando os espaços pedagógicos e familiares, nos países europeus, entre as tecnologias políticas que irão investir sobre o corpo, a saúde, as formas de se alimentar e de morar, a existência da criança. Os estudos de Foucault $(1979,2008)$ a respeito dos mecanismos de poder constituídos a partir dos séculos XVII e XVIII possibilitam refletir sobre essas formas de governar a vida constituídas na relação com o Estado. Esta arte de governar se estabelece, conforme Foucault (2008), à medida que o Estado passa a operar a função de segurança através da polícia, cuja estratégia possibilita o crescimento das forças do Estado através da manutenção da ordem, incluindo um conjunto de 
relações que envolvem as condutas, os valores morais, a conservação de um modo de viver, as formas de cuidado e de disciplina. Destaca-se aqui que o contexto histórico desta problematização envolve a relação do Estado com o homem moderno, portanto determinados modos de viver a liberdade, pois a "A integração das liberdades e dos limites próprios a essa liberdade no interior do campo da prática governamental tornou-se agora um imperativo" (FOUCAULT, 2008, p. 475).

Os procedimentos de poder colocados em prática na sociedade moderna são numerosos e diversos em suas formas de gerir a vida. Segundo Foucault (1979), encontramos tanto o princípio da visibilidade-vigilância que evidencia toda uma tecnologia do poder; como também uma organização do espaço direcionada ao alcance de objetivos econômico-políticos, cuja arquitetura específica articula seu funcionamento aos problemas da população, da saúde e do urbanismo. Segundo Donzelot (1986, p. 12), são “Técnicas que, no seu ponto de partida, encontram seu polo de unificação naquilo que então se chamava de polícia”, mas não somente no sentido repressivo, envolvendo uma concepção mais ampla que vai abarcar "todos os métodos de desenvolvimento da qualidade da população e da potência da nação".

Ariès (1981) destaca a organização do espaço urbano, na constituição da vida moderna, que tem por função cultivar este "sentimento novo entre os membros da família, e mais particularmente entre a mãe e a criança: o sentimento de família" (ARIĖS, 1981, p. 25). O autor situa em seus estudos, considerando fontes francesas, no fim do século XVII e início do XVIII, que a vida familiar é organizada longe da rua, da praça, da vida coletiva, e dentro de uma casa melhor defendida contra intrusos e preparada para a intimidade. A organização do espaço privado tinha forma na arquitetura das casas, cujos cômodos passaram a se comunicar por meio de um corredor em lugar de se abrirem um para outro, bem como com uma especialização funcional - como sala de visita, própria ao estranho, e quarto de dormir, destinado à intimidade.

Goldthwaite (apud ARIÈS, 1981, p. 25) ressalta a presença na arquitetura florentina de "uma relação muito precisa entre o início do sentimento da família e da criança e uma organização particular do espaço", sendo evidenciado um interesse nas posições ocupadas pelas mulheres e crianças, bem como nas formas de educação. Neste estudo dos palácios florentinos dos séculos XIIIXIV, Ariès (1981), encontra uma organização do espaço em que a vida pública e a vida familiar se prolongavam uma na outra, sendo que a construção pouco se distinguia de sua vizinhança urbana. Havia a torre destinada à defesa e o andar térreo com varandas onde parentes, amigos e clientes se reuniam para participara da vida pública do bairro, bem como onde feiras e o comércio aconteciam. As peças atribuídas à família principal prolongavam-se pela casa ao lado, enquanto alguns locatários ocupavam partes centrais. Já no século XV esta construção teve sua planta modificada, o palácio tornou-se uma unidade, "um maciço solto da vizinhança" (ARIÈS, 1981, p.23), sendo que tanto as lojas como os ocupantes estranhos desapareceram.
O autor analisa que esses movimentos de reorganização da casa e de mudança dos costumes evidenciam um espaço maior para a intimidade em que a família é reduzida aos pais e às crianças, excluindo criados, clientes e amigos. Ariès (1981) identifica este processo como uma passagem da família medieval à família moderna, retraindo a sociabilidade constituída no convívio com as demais relações na sociedade, movimento que seria mais rápido na burguesia, do que nas classes populares, pois respondia aos objetivos econômico-políticos que produzia um modo ideal de vida familiar burguesa que viria a ser disseminado como modelo de vida. "No século XVIII, a família começou a manter a sociedade à distância, a confiná-la a um espaço limitado, aquém de uma zona cada vez mais extensa da vida particular" (ARIÈS, 1981, p. 265), sendo que a compreensão de nossos costumes contemporâneos passa pela análise deste crescimento do sentimento direcionado às relações familiares.

Foucault (1979) afirma essa diferenciação na lógica de organização do espaço, no final do século XVIII, como um dos mecanismos para articular os objetivos econômicopolíticos com as demandas da população e da vida urbana, tornando-se necessário fazer circular os efeitos do poder por canais cada vez mais sutis, chegando até os próprios indivíduos, seus corpos, seus gestos, cada um de seus desempenhos cotidianos. Neste sentido, o autor destaca a importância dos estudos de Philippe Ariès a respeito de como a casa passa de um espaço indiferenciado para e torna-se funcional. Foucault (1979) traz como exemplo desta mudança, na edificação das cidades operárias dos anos 1830-1870, a prescrição de um tipo de moralidade direcionada à família operária que se materializa em seu espaço de vida através da determinação das peças e seus respectivos usos: cozinha, sala de jantar, quarto dos pais o lugar da procriação - e quarto das crianças.

Podemos indagar, então, como essa arquitetura da casa e das relações sociais na cidade vai sendo articulada com a presença da criança, considerando as diferenças de classe que vão sendo definidas neste momento histórico para constituir a noção de infância. Donzelot (1986, p. 15) demarca a presença forte, a partir do século XVIII, do discurso que trata da "conservação de crianças" enunciado com destaque por médicos e administradores, considerando preceitos educativos que visam "três alvos privilegiados: a prática dos hospícios dos menores abandonados, a da criação dos filhos pelas amas-de-leite, a da "educação 'artificial' das crianças ricas". Para o autor, o advento da família moderna centrada no primado educacional, seguiu duas linhas distintas de acordo com as classes sociais, representadas pela família burguesa e a família popular:

A família burguesa constituiu-se através de um retraimento tácito de seus membros com o objetivo de recalcar ou controlar um inimigo do interior: os serviçais. Através dessa coesão ela se atribuiu um excesso de poder que a eleva socialmente, permitindo-lhe retornar ao campo social com mais força, para aí exercer diversos controles e patrocínios. A aliança com o médico reforça o poder interno da mulher e mediatiza o poder externo da família. Ao passo que a família popular se amolda a partir de uma redução de 
cada um de seus membros aos outros, numa relação circular de vigilância contra as tentações do exterior, o cabaré, a rua. Ela realiza suas novas tarefas educativas às custas de uma perda de sua coextensividade com o campo social de uma separação de tudo aquilo que a situava num campo de forças exteriores. Isolada, ela se expõe, doravante, à vigilância de seus desvios (DONZELOT, 1986, p. 46-47).

Quanto à infância na trama destas relações de poder, Donzelot (1986) relaciona a presença de uma liberação protegida na família burguesa, em que a questão é delimitar seu campo de desenvolvimento; enquanto na família popular, a questão é introduzir uma liberdade vigiada para limitar a liberdade e dirigir a criança para espaços de maior vigilância, como a escola ou a casa, ou ainda, os abrigos. Esse funcionamento é mantido com relações de poder conectadas ao dispositivo disciplinar, estudado por Foucault (1987) a partir do mecanismo

panóptico proposto por Bentham (2000), que ao planejar a arquitetura de vigilância prisional, desenvolve uma tecnologia de poder própria para resolver os problemas de vigilância demandados no funcionamento institucional da sociedade moderna, os quais passam a ser utilizados nas escolas, fábricas, hospitais, entre outros estabelecimentos. Segundo Foucault (1987) o dispositivo disciplinar produz meios de enclausuramento e de vigilância de si que passam a controlar os corpos e normatizar modos de ser, arranjo de saberes que conduz condutas e regime de verdade que o naturaliza como único a ser praticado. $\mathrm{O}$ autor destaca que estes novos arranjos que fazem funcionar a sociedade estão relacionados com o fato de que a burguesia compreende perfeitamente que uma nova legislação ou uma nova constituição não são suficientes para garantir sua hegemonia, sendo necessário inventar uma nova tecnologia para assegurar os efeitos do poder por todo o corpo social, até mesmo em suas menores partículas (FOUCAULT, 1979).

Os autores com os quais dialogamos analisam como o espaço citadino na relação com a infância constitui um importante mecanismo de governo no qual é evidenciado um deslocamento do espaço e significado da família na sociedade moderna e que ressoa até os dias atuais. Este deslocamento diz respeito ao modo como o espaço familiar passa de um funcionamento que possibilita as relações com a rua e os ensinamentos dessa convivência, para uma arquitetura que evidencia fronteiras que vão projetando a casa e uma organização espacial da vida privada com novas funções para a criança e o adulto, para os pais e os filhos, conforme nos indica Ariès (1981). Nesse movimento de relações, a infância vai sendo inventada em um espaço doméstico e nas suas formas de alojar a família. Lembrando que para Donzelot (1986, p. 13) a família "é uma instância cuja heterogeneidade face às exigências sociais pode ser reduzida ou funcionalizada através de um processo de flutuação", o que nos leva a um atento olhar sobre como acontece sua "circularidade funcional entre o social e o econômico".

É a partir desse complexo processo de relações, que se naturalizam espaços no desenrolar de nossas práticas, governando saberes, que passamos a problematizar o cotidiano citadino na vida das crianças. Assim, a análise das condições da produção histórica em relação ao modo de olhar a infância e a cidade, no jogo das relações de poder, contribui para analisarmos como se produzem as práticas de proteção e de controle da infância nas legislações que tratam da criança no contexto brasileiro.

\section{Legislações brasileiras da Infância como analisadores da relação Infância/Cidade}

No Brasil, o que tem sido chamado de proteção para a infância e a adolescência é regulado por legislações que marcaram nossa história sobre essa temática ao longo do século XX. São três os principais marcos legais, tomados aqui como analisadores de nossas problematizações sobre as relações infância/cidade, ao buscar pensar as propostas de garantia de direitos para essa população e os trajetos que a cidade constrói para ela.

\subsection{Que cidade é enunciada nos códigos}

Em 1927 é promulgada no Brasil a primeira lei específica para crianças e adolescentes, o Código de Menores. Tal legislação surge com o objetivo de regulamentar a assistência ao chamado menor e emerge a partir da associação entre os discursos dos médicos higienistas, preocupados com a prevenção e com a produção de novas formas de controle da sociedade, e dos juristas da época, atentos ao grande número de crianças que perambulavam pelas ruas e inquietos com o aumento da chamada criminalidade infantil. Vemos, então a emergência de uma lei que se destina a uma infância específica, a infância pobre, que não deveria circular pela cidade, não deveria fazer parte da paisagem urbana. Era preciso invisibilizá-la, cobri-la com as paredes e os muros dos internatos. É uma população composta por aqueles que passam a ser nominados menores, em diferenciação aos que são chamados crianças. Uma população identificada como elemento de desordem, tomada como uma ameaça à sociedade e ao futuro da nação por apresentar modos de existência não compatíveis com a chamada vida certa. Dessa maneira, por meio de um aparato jurídico, vai se produzindo uma cidade higienizada da incômoda presença de uma infância tida como perturbadora e virtualmente perigosa. É no texto da lei que encontramos essas considerações:

Art. 28. São vadios os menores que:

a) vivem em casa dos paes ou tutor ou guarda, porém, se mostram refractarios a receber instruccão ou entregar-se a trabalho sério e util, vagando habitualmente pelas ruas e Iogradouros publicos;

b) tendo deixado sem causa legitima o domicilio do pae, mãe ou tutor ou guarda, ou os Iogares onde se achavam collocados por aquelle a cuja autoridade estavam submettidos ou confiados, ou não tendo domicilio nem alguem por si, são encontrados habitualmente a vagar pelas ruas ou logradouros publicos, sem que tenham meio de vida regular, ou tirando seus recursos de occupação immoral ou prohibida.

Art. 112. Nenhum varão menor de 14 anos, nem mulher solteira menor de 18 anos, poderá exercer occupação alguma que se desempenho nas ruas, praças ou logares públicos; 
sob pena de ser apprehendido e julgado abandonado, e imposta ao seu responsável legal $50 \$$ a $500 \$$ de multa e dez a trinta dias de prisão cellular (BRASIL,1927).

Tal lógica perdura por mais de 50 anos, até que em 1979, em pleno período de ditadura, os militares propõem uma reformulação no Código, nele incluindo o que foi intitulado de infância em situação irregular. É bom lembrar que a ditadura civil-militar de 1984 decreta que crianças e adolescentes são um problema de segurança nacional e para regular tal questão é implantada a Política Nacional de Bem-Estar do Menor - PNBEM (BRASIL, 1964), seguindo o parâmetro de ordem, desenvolvimento e segurança imposto pela Lei de Segurança Nacional, vigente no país à época. Assim sendo, os chamados menores eram considerados uma possível ameaça à ordem social e à segurança da nação, pois poderiam se tornar criminosos, malandros, e sobretudo subversivos, enfim fazer parte do que era então chamado de "inimigos internos". O Código de 1979 pouco alterou o texto da lei anterior, mas ao trazer a lógica da situação irregular assumiu a função de garantir a segurança do país através do controle dos considerados menores abandonados ou delinquentes, Ou seja, aqueles que escapavam da vida certa e que na maioria dos casos já se encontravam internados sob os auspícios da FUNABEM (Fundação Nacional do Bem-Estar do Menor) e das FEBEMs (Fundação Estadual do Bem-Estar do Menor), órgãos normativos e executivos montados pela ditadura, que formavam o grande complexo tutelar ocupado em fazer desaparecer das ruas das grandes cidades os rostos infanto-juvenis dos pobres. Dentro dessa lógica, foram reformados os velhos internatos estatais visando mais uma vez afastar do espaço urbano o perigo que a pobreza poderia disseminar. E, assim, se fortalece a relação cidade-infância-invisibilidade, que torna normal o enclausuramento de vidas consideradas errantes.

$\mathrm{Na}$ segunda metade dos anos de 1980 emergem movimentos sociais que resistem ao modelo anterior dos Códigos de Menores. Como efeito de suas lutas, é promulgado em 1990 o Estatuto da Criança e do Adolescente, que se pauta na política da proteção integral. $\mathrm{Na}$ análise que fazemos aqui, cabe destaque a um ponto do Estatuto: a frequente referência que faz à defesa do direito à convivência comunitária. Pode-se dizer que nessa nova legislação se fez atenção à possibilidade de circulação, à possibilidade de se misturar com aquilo que se passa fora dos muros fechados dos estabelecimentos de acolhimento. Ou seja, que finalmente afirma-se um modo de vida que conecta a criança com a paisagem urbana, que a vincula com pessoas, com lugares, com costumes, com traçados citadinos.

Mas como são acolhidos aqueles a quem sempre foram destinados os espaços fechados (internatos, abrigos, casas de recolhimento)? É comum a rejeição, pelos vizinhos, da implantação de estabelecimentos de acolhimento institucional para crianças e adolescentes. A subjetividade hegemônica reproduzida em modelos padronizados de viver informa que a presença daqueles diferentes vai desvalorizar os imóveis da região, vai trazer violência e insegurança para o bairro. Em resumo: não é bom para aquele espaço urbano que determinadas crianças e adolescentes marquem suas presenças nos movimentos da cidade. Há um jogo de forças que favorece suas permanências atrás dos muros, em lugares fechados, nos quais espera-se tenham uma visibilidade menor, forjada por práticas de controle.

Os muros que vão sendo demarcados não dizem respeito apenas aos estabelecimentos administrados pelas políticas de Estado. Os territórios da cidade também vão sendo esquadrinhados entre bairros próximos aos espaços centrais da cidade e aqueles periféricos, entre movimentos que aproximam e distanciam uns e outros, conforme a mobilidade possível para percorrer calçadas, ruas, bairros.

\subsection{Que cidade é enunciada no Estatuto da Criança e do Adolescente - ECA}

O ECA emerge pela lógica da criança cidadã ao ressaltar a importância de seus direitos. Desse modo, a legislação, ao dizer que a criança e o adolescente são sujeitos de direitos, determina um conjunto de práticas que definem suas relações com o mundo: como devem ser cuidados, escolarizados, preparados para o futuro profissional; enfim um jogo contínuo de disciplinarização de condutas. Essa prática se dá em um lugar dito adequado, em um espaço privado, a família. Nela e nos demais espaços institucionais de cuidado de crianças e adolescentes - a escola, o abrigo, o estabelecimento de internação - a condição de proteção vai sendo associada ao ordenamento de uma vida privada que estabelece uma barreira com as relações da vida pública. Como constituir um sujeito de direito em uma condição sempre "mediada" pelo adulto, pela norma, pelos muros do estabelecimento?

Isso se dá porque o estado de sujeito de direitos se estabelece a partir de determinadas concepções ordenadoras do Estatuto, dentre elas a condição de crianças e adolescentes serem pessoas em desenvolvimento. Por essa lógica, a defesa dos direitos segue a diretriz da antecipação do futuro a favor da prevenção de riscos e está vinculada a um processo de maturação. Uma visão hegemônica do modo de ser adolescente/ criança, a desenvolvimentista, não considera a produção de outros sentidos de infância e de adolescência que escapam a padrões, tendo em vista que a vida vai sendo construída a todo momento, a cada encontro e a partir dos acasos (GONZÁLES; GUARESCHI, 2009). A visão desenvolvimentista, ressaltada no Estatuto, coloca a população infanto-juvenil em um lugar de fragilidade naturalmente definida por serem pessoas de pouca idade.

Portanto, é por meio da tutela que a legislação considera crianças e adolescentes como sujeitos detentores de direitos civis humanos e sociais, afirmando em seu artigo 18 que "é dever de todos velar pela dignidade da criança e do adolescente, pondo-os a salvo de qualquer tratamento desumano, violento, aterrorizante, vexatório ou constrangedor" (BRASIL, 1990). Com isso o ECA implanta mecanismos jurídicos para efetivar junto a essa população os direitos determinados pela Declaração Universal dos Direitos Humanos de 1948. Vale dizer, 
também, que o Estatuto tem como base os chamados direitos fundamentais, ou seja, aqueles consagrados constitucionalmente, que têm como ideia central um molde perfeito ao qual as práticas cotidianas devem submeter-se.

A noção de direitos convoca todos a participar e viver segundo seus preceitos e é a partir dela que se estruturam as relações sociais e a ideia de cidadania. Uma afirmação de Fonseca, D. (1997) pode dar início às considerações a serem feitas aqui sobre o tema. A autora entende a concepção de cidadania como "uma produção histórica, um conjunto de práticas, um modo de subjetivação ao qual corresponderá o aparecimento de um tipo de corpo: o cidadão" (FONSECA, D., 1997, p. 2).

Em sua versão moderna liberal a cidadania supõe inclusão, condição priorizada pelo Estatuto ao optar pela doutrina da proteção integral. Trata-se de um paradigma baseado em uma moralidade de direitos. Ou seja, o corpo cidadão é um modelo construído em cima da tradicional figura do homem moralizado que emerge na ordem liberal.

A passagem da legislação menorista brasileira para outra que atribui à criança a condição de cidadã se deu pela participação ativa dos movimentos sociais na década de 1980. Apostando nos princípios da Constituição Federal de 1988, esses movimentos concentraram seus esforços no combate à centralização jurídica e social dos espaços de assistência à população infanto-juvenil, investindo na participação da sociedade civil, em especial nos conselhos paritários, inovação trazida pela referida Constituição. A luta desses movimentos se baseava no argumento que essa população estava submetida a um sistema jurídico perverso, que se revelava extremamente opressivo e repressor. Propagavam a necessidade de extinção da Doutrina da Situação Irregular e a instauração de uma outra, a da Proteção Integral. Reprovavam o sistema de justiça menorista, por ser punitivo, patologizante e penalizador da pobreza; e se organizaram para construir um outro sistema de garantia de direitos, que no contexto do Estado liberal, afirmava uma ideia abstrata de cidadania. Nessa direção estavam articulados associações de moradores, organizações religiosas, o Movimento Nacional de Meninos e Meninas de Rua, centros de defesa de direitos humanos, dentre outros equipamentos da sociedade civil organizada, nos seus diferentes núcleos de estudos e de defesa dos direitos.

A criança está na cidade constituída pelos estabelecimentos destinados a uma condição de proteção da infância: a casa, a escola, o abrigo, o estabelecimento de internação. Da família aos demais laços institucionais a condição de proteção vai sendo associada ao ordenamento de uma vida privada que estabelece uma barreira com as relações da vida pública, embora a condição de sujeito de direito que envolve o exercício da participação que ultrapassa as fronteiras instituídas da circulação de sua voz e de seus passos. Como constituir um sujeito de direito numa condição sempre "mediada-interditada" pelo adulto, pela norma, pelos muros do estabelecimento?

\section{Imagens que atualizam as tensões entre tempos citadinos: $\mathrm{O}$ que aconteceu com meus direitos?}

Se as crianças conseguissem que seus protestos, ou simplesmente suas questões, fossem ouvidos em uma escola maternal, isso seria o bastante para explodir o sistema de ensino. Na verdade esse sistema em que vivemos nada pode suportar, dai sua fragilidade radical em cada ponto, ao mesmo tempo sua força global de repressão (DELEUZE, 1979, p. 72).

As imagens emblemáticas iniciais enunciam um modo como a criança está na cidade, constituindo um determinado regime de visibilidade. Ao trazermos este enunciado da violação de direitos em confronto com o marcador que legislamos para proteger e acolher a infância brasileira, com o meio marcado pelo espaço constituído como um modo de governar a infância na sociedade moderna, desdobramos a narrativa citadina a ser percorrida pela arquitetura em que a infância foi sendo experimentada.

Memória que a imagem trás e nos alerta. Assim, atualizamos nossa problematização da infância entre questões que indagamos e nos indagam sobre a vida que nos cerca e nos arrasta entre casas, escolas, abrigos, ruas, espaço que dá forma às políticas que movem a vida. $\mathrm{Na}$ atualidade brasileira, entre as linhas que compõe o jogo de forças uma enunciação: "O ECA não funciona". As disputas que marcaram a produção deste documento permanecem em combate evidenciado um território de luta entre modos de praticar a política e pensar a infância e juventude brasileiras. Outros modos de pensar a experiência da infância e de instituir o espaço citadino têm sido problematizados em diferentes possibilidades que acolhem a invenção de nossos modos de viver na produção de conhecimento brasileira (FONSECA, C., 2005; KOHAN, 2007; CECCIM; PALOMBINI, 2009; MEDEIROS; LEMOS, 2011).

Código e ECA; Menor e Sujeito de Direito; Família e Estado; Casa e Cidade; Privado e Público; séries que podem ser abordadas como presenças ou ausências de nosso tempo, numa lógica excludente e binária, ou posicionar tensões que marcam paradoxos como forças que subjetivam ao mesmo tempo que nos levam a experimentar esta relação e mapear os movimentos que nos produzem neste espaço-tempo. Ao construirmos a presente reflexão para pensar como são constituídos os arranjos entre a infância e a cidade a partir de um modo de produção das relações de poder, encontramos os modos de governar a vida no encontro da geografia do espaço com a cartografia dos modos de enunciar e visibilizar a criança.

No processo de escrita deste texto, indagamos o quanto o verbo inventar, enunciado em seu título, havia sido conjugado entre os sentidos que percorriam o passado e o presente no encontro entre a infância e a cidade. A pista de Agamben (2009, p. 70) nos indica que o contemporâneo implica a experiência de uma descontinuidade que interpola o tempo para colocá-lo, exatamente, “em relação com os outros tempos, de nele ler de modo inédito 
a história, de citá-la segundo uma necessidade que não provém de maneira nenhuma de seu arbítrio, mas de uma exigência à qual ele não pode responder".

Ao compormos esse movimento no tempo, percorrendo neste estudo o sentimento de família e o sentimento de infância produzidos pela vida moderna, e os registros das diretrizes de referência na política da infância no Brasil, lançamos nosso olhar para um diagrama que vem constituindo um "sentimento de sujeito de direito infantojuvenil". Essa possível condição, constituída na exigência de práticas de pesquisa com políticas juvenis que solicitam análise, e que foi inventada na genealogia desta escrita, nos traz outros elementos para pensar como a criança é dita e vista entre políticas e saberes que produzem modos de viver a cidade nos arranjos do contemporâneo.

\section{Referências}

AGAMBEN, G. O que é o contemporâneo? e outros ensaios. Chapecó, SC: Argos, 2009.

ARIÈS, P. História social da criança e da família. Rio de Janeiro: LTC, 1981.

BENTHAM, J. O panóptico. Belo Horizonte: Autêntica, 2000.

BRASIL. Presidência da República. Casa Civil. Subchefia para Assuntos Jurídicos. Decreto 17.943A de 12 de outubro de 1927. Consolida as leis de assistência e protecção a menores. Revogado pela Lei $\mathrm{n}^{\circ}$ 6.697, de 1979. 1927. Disponível em: <http:// www.planalto.gov.br/ccivil_03/decreto/1910-1929/ D17943Aimpressao.htm>. Acesso em: 4 abr. 2014.

BRASIL. Presidência da República. Casa Civil. Subchefia para Assuntos Jurídicos. Lei $n^{\circ} 4.513$, de 01 de dezembro de 1964. Autoriza o Poder Executivo a criar a Fundação Nacional do Bem-Estar do Menor, a ela incorporando o patrimônio e as atribuições do Serviço de Assistência a Menores, e dá outras providências. Revogado pela Lei $\mathrm{n}^{\circ}$ 8.069, de 1990. 1964 Disponível em: <http://www.planalto.gov.br/ccivil_03/ leis/1950-1969/L4513.htm> Acesso em: 4 abr. 2014.

BRASIL. Presidência da República. Casa Civil. Subchefia para Assuntos Jurídicos. Lei $n^{\circ} 6.697$ de 10 de outubro de 1979. Institui o Código de Menores. Revogada pela Lei $\mathrm{n}^{\circ} 8.069$, de 1990. 1979. Disponível em: <http://www.planalto. gov.br/ccivil_03/leis/1970-1979/L6697impressao. htm>. Acesso em: 4 abr. 2014.

BRASIL. Presidência da República. Casa Civil. Subchefia para Assuntos Jurídicos. Lei $n^{\circ}$ 8.069, de 13 de julho de 1990 Dispõe sobre o Estatuto da Criança e do Adolescente e dá outras providências. 1990. Disponível em: <http://www. planalto.gov.br/ccivil_03/leis/18069.htm>. Acesso em: 4 abr. 2014

CECCIM, R. B.; PALOMBINI, A. L. Imagens da infância, devir-criança e uma formulação à educação do cuidado. Psicologia \& Sociedade, [S.1.], v. 21, n. 3, p. 301-312, set./dez. 2009.

CORAZZA, S. M. Histórias da infância sem fim. Ijuí: Unijuí, 2000.

DELEUZE, G. Foucault. São Paulo: Brasiliense, 1988.

DELEUZE, G. Os intelectuais e o poder: conversa entre Michel Foucault e Gilles Deleuze. In: FOUCAULT, M. Microfisica do poder. Rio de Janeiro: Graal, 1979. p. 69-78.

Fractal, Rev. Psicol., v. 28 - n. 2, p. 257-265, 2016
DONZELOT, J. A polícia das famílias. Rio de Janeiro: Graal, 1986.

FONSECA, C. Concepções de família e práticas de intervenção: uma contribuição antropológica. Saúde e Sociedade, São Paulo: v. 14, n. 2, p. 50-59, maio/ago. 2005.

FONSECA, D. F. Avessos de cidadania: um exercício analítico. Dissertação (Mestrado)-Pontifícia Universidade Católica de São Paulo, São Paulo, 1997.

FOUCAULT, M. Microfisica do poder. Rio de Janeiro: Graal, 1979.

FOUCAULT, M. Vigiar e punir: nascimento da prisão. Petrópolis: Vozes, 1987.

FOUCAULT, M. Mesa-redonda de 20 de maio de 1978. In: MOTTA, M. B. da (Org.). Estratégia, poder-saber. Rio de Janeiro: Forense/Universitária, 2003. Coleção Ditos \& Escritos, v. 4 , p. $335-354$.

FOUCAULT, M. Segurança, território, população. São Paulo: Martins Fontes, 2008

GONZÁLES, Z. K.; GUARESCHI, N. M. F. Concepções sobre a categoria juventude: paradoxos e as produções nos modos de ser jovem. In: CRUZ, L. R.; GUARESCHI, N. (Org.). Políticas públicas e assistência social: diálogo com as práticas psicológicas. Petrópolis, RJ: Vozes, 2009. p. 104-123.

GOUVÊA, M. C. S; JINZENJI, M. Y. Escolarizar para moralizar: discursos sobre a educabilidade da criança pobre (1820-1850). Revista Brasileira de Educação, Rio de Janeiro, v. 11, n. 31, p. 114-200, jan./abr. 2006.

KOHAN, W. O. Infância, estrangeiridade e ignorância: ensaios de filosofia e educação. Belo Horizonte: Autêntica, 2007.

LAZZAROTTO, G. D. R. Políticas Juvenis e Subjetividade: interfaces com a psicologia. In: LAZZAROTTO, G. D. R.; CRAYDI, C. M.; OLIVEIRA, M. M. (Org.). Processos educativos com adolescentes em conflito com a lei. Porto Alegre: Mediação, 2012. p. 157-167.

LAZZAROTTO, G. D. R. Medidas socioeducativas: cartas ao reinado do saber. Psicologia em Estudo, Maringá, v. 19, n. 3, p. 503-514, jul./set. 2014.

MEDEIROS, L. G; LEMOS, F. C. S. A produção da "circulação de crianças": entre capturas e nomadismos. Estudos e Pesquisa em Psicologia, Rio de Janeiro, v. 11, n. 3, p. 933-947, 2011.

NASCIMENTO, M. L. Crianças e adolescentes marcados pela defesa dos direitos. Revista Ecopolítica, n. 8, p. 19-40, jan.abr. 2014a. Disponível em: <http://revistas.pucsp.br/index.php/ ecopolitica/article/view/19460/14422>. Acesso em: 13 fev. 2015.

NASCIMENTO, M. L. Pelos caminhos da judicialização: lei, denúncia e proteção no contemporâneo. Psicologia em Estudo, Maringá, v. 19, n. 3, p. 459-467, jul./set. 2014b.

SCHÉRER, R. Infantis: Charles Fourier e a infância para aléns das crianças. Belo Horizonte: Autêntica, 2009.

VIDA de doze meninos no esgoto de Porto Alegre, A. Zero Hora, Porto Alegre, 1 maio 1993. Ano XXIX, n. 10114, Capa. Fotografia de Genaro Joner.

Recebido em: 5 de maio de 2015 Aceito em: 7 de julho de 2016 